\title{
STUDY OF MECHANICAL AND MORPHOLOGICAL PROPERTIES OF GLASS FIBER REINFORCED MODIFIED EPOXY COMPOSITES
}

\author{
K.Natarajan ${ }^{1}$, Padma C Balasubramanya ${ }^{2}$ \\ ${ }^{1}$ Professor, ${ }^{2}$ Research Scholar, R.V. College of Engineering, Bangalore, India
}

\begin{abstract}
Polymethylmethacrylate and Poly (acrylonitrile-co-butadiene) rubber were used to modify Diglycidyl ether of bisphenol A (DGEBA) type epoxy resin and cured with stoichiometric quantities of the hardener 4,4' diamino dipheny methane. This modified epoxy resin was used as the matrix for the preparation of glass fiber reinforced composites. E-Glass fiber was used as fiber reinforcement. The morphology and mechanical properties of the composite analysed.

Morphological analysis of the fractured surface of the composites indicated good adhesion between the matrix polymer and the glass fibers. Hence an enhancement in mechanical properties of the composite such as tensile, flexural, impact and fracture toughness has been observed as there has been an effective transfer of the load from the matrix to the fiber. Hence these composites which exhibit high toughness, strength and dimensional stability can be envisaged to provide valuable contribution to high performance structural applications.
\end{abstract}

Keywords: Glass composites, mechanical properties, modified epoxy matrix, morphology and ternary blend - ****

\section{INTRODUCTION}

Thermosetting polymers such as epoxy resins are the most widely used for applications such as matrices for fiber reinforced composites, coatings, structural adhesives and other engineering applications [1-3]. These materials provide high durability, design flexibility and light weight which make them attractive materials in these applications [4]. However their inherent brittleness constrains many of its applications.

Over the years several investigations have been aimed on toughening of epoxy thermosets without sacrificing its other properties. One such modifications method is the incorporation of secondary rubbery phase that separates from the matrix during cure leading to different morphologies [5-8]. The advantage of adding rubber is increase in fracture toughness drastically at the expense of great reduction in the modulus and thermal stability of the material. The second method of toughening is to introduce high performance thermoplastics [9-11]. However it has been shown that the thermoplastic modified epoxies exhibit various types of morphology, depending crucially on the backbone structure, molecular weight and the end group chemistry of the thermoplastic. Since the ultimate properties of the blend is dependent on the morphology of the cured resin, the difficulty of controlling morphology limits any further improvement of toughness using the thermoplastics.
Thermosets have historically been the principal matrix material for composites. The use of epoxy resins as the matrix for fiber reinforced composites in structural applications has increased significantly. This is because fiber reinforced composites provide a combination of strength and modulus that are either comparable or better than many of the conventional metallic materials. Among the fibers used in composites glass fiber is most common as it is one among the high strength and high modulus material. Further, glass fibers provide advantages such as low cost, high tensile strength, high chemical resistance and excellent insulation properties. There are mainly two types of glass fibers commonly used in fiber reinforced plastic industry, namely E-glass and S-glass. E-glass has the lowest cost of all commercially available reinforcing fibers, which is the reason for its wide spread application in fiber reinforced composite industry.

The current research is directed towards preparation of E-glass composite using a modified epoxy matrix. The modified epoxy resin matrix has been developed by incorporating five parts per hundred of the thermoplastic, polymethylmethacrylate [PMMA] and five parts per hundred of the elastomer, poly (acrylonitrile-co-butadiene) rubber [NBR] into the epoxy matrix. Mechanical and morphological investigations of this modified epoxy resin matrix have revealed a significant enhancement in mechanical properties without sacrificing the thermal properties. The objective of the present work is to investigate the morphological and 
mechanical properties of this glass fiber reinforced modified epoxy composite [GFRMEC].

\section{EXPERIMENTATION}

\subsection{Materials}

All materials used throughout this work were from commercial sources and were used as received. The epoxy resin employed was Epicote 828 comprising bisphenol A and epichlorohydrin as kindly supplied by Veeyor polymer private limited, Bangalore. The resin had an epoxy equivalent of $188.5 \mathrm{~g} / \mathrm{mol}$. The thermoplastic used was polymethylmethacrylate (PMMA) IH830, a product of LGMMA. The rubber used here was nitrile- butadiene rubber, TAPRYL CC-360, with a bound acrylonitrile content of $32 \%$ kindly supplied by Taprath Polymers Pvt. Ltd. Mumbai, India. The curing agent 4, 4'diamino diphenyl methane (DDM) ,K-5 is a product of Atul polymer Ltd, Gujarat, India. The E-glass fiber [bi-woven, $360 \mathrm{gsm}$ ] was commercially obtained.

\subsection{Fabrication of the Composite}

First, the rubber and epoxy component were mixed in dichloromethane/methanol $90 / 10 \mathrm{v} / \mathrm{v}$, and the solution was stirred for approximately 30 minutes to achieve dissolution. The thermoplastic was dissolved in the same mixed solvent combination and this solution was filtered into the epoxy/rubber mixture. It was then heated to remove excess of solvent and then DDM was added to the mixture at $80 \%$ stoichiometrically. This mobile modified epoxy matrix was then poured uniformly over the fibers placed manually on the mould prepared according to ASTM standard D3039-76.The mould contained a steel plate covered with a Teflon sheet. A thin coat of modified resin matrix was first applied to this Teflon sheet and then the first ply was placed and the modified resin matrix poured. Subsequently remaining piles were stacked, aligned in the wrap direction and impregnated with the modified resin matrix. Great care was taken in ensuring that there was no disruption of the fiber alignment. Rollers were used to densify the lay-up, thoroughly wetting the glass fibers with the modified epoxy matrix and to remove excess matrix and entrapped air. This laminate was then built up layer by layer until the required thickness. The laminate was then cured at $1150 \mathrm{C}$ in an air oven for a period of 4 hours. It was then post cured at $1200 \mathrm{C}$ for 2 hours and then gradually cooled by placing it in the oven overnight.

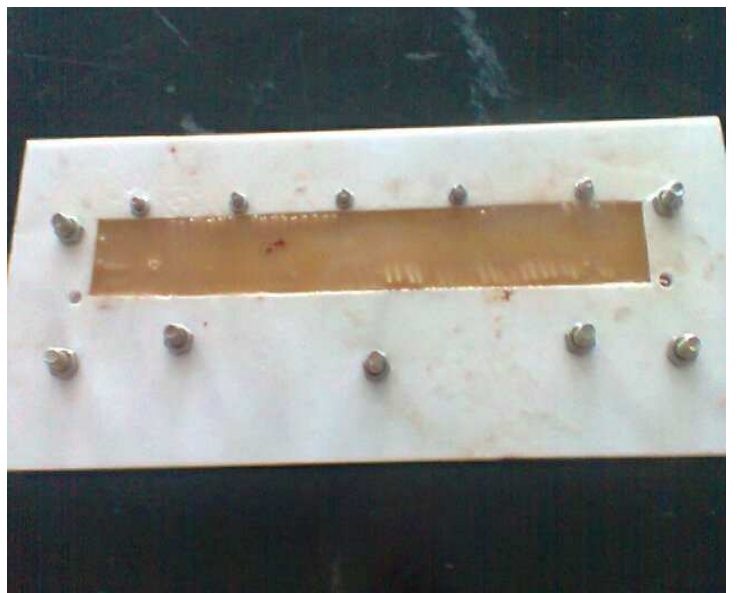

Fig 1: Teflon mould containing the cured glass fiber reinforced modified epoxy composite \{GFRMEC

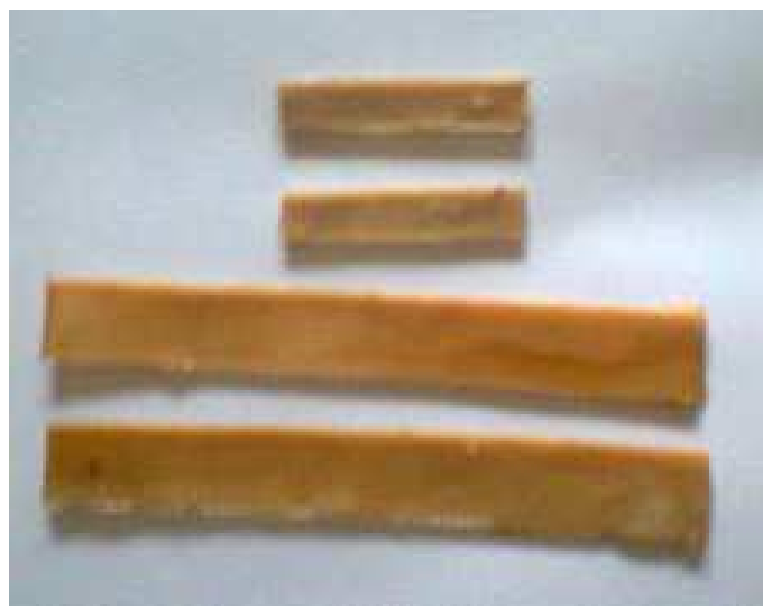

Fig 2: GFRMEC removed from the mould

\section{CHARACTERISATION}

\subsection{Mechanical Testing}

\subsubsection{Tensile Strength}

The tensile tests were performed in an Instron testing machine at a cross head speed of $5 \mathrm{~mm} / \mathrm{min}$ according to ASTM D303976. The values were taken from an average of at least 5 specimens.

\subsubsection{Impact Strength}

The impact strength of the notched specimens was determined using rectangular species of $64 \times 12.7 \times 3.2 \mathrm{~mm}^{3}$ according to ASTM D256. The impact test was carried out at room temperature and the impact energy was reported in Joules per meter. The values were taken for an average of at least 5 specimens. 


\subsubsection{Flexural Properties}

Flexural tests were performed with rectangular samples according to ASTM D-790 using an Instron testing machine, fitted with a three -point bending fixture at a cross head speed of $2 \mathrm{~mm} / \mathrm{min}$. The dimensions of the samples were $100 \times 10 \times 5 \mathrm{~mm}^{3}$.

\subsubsection{Fracture Toughness}

Fracture toughness, $\mathrm{K}_{\mathrm{IC}}$, measurement were done on singleedge notched bend specimens [SEN-B] in an Instron machine at a cross head speed of $5 \mathrm{~mm} / \mathrm{min}$, according to ASTM D5045 , for the sample size of $60 \times 12 \times 3 \mathrm{~mm}^{3}$ with the length of the notch equal to $6 \mathrm{~mm}$. Before the measurements the cuts were made sharper by using a laser blade.

\subsubsection{Scanning Electron Microscopy}

The morphology and fracture surface of the blends were studied using scanning electron microscope [Quanta 200, FEINetherland] at an accelerating voltage of $20 \mathrm{kV}$. The specimens were sputtered with gold before taking the micrographs.

\section{RESULT AND DISCUSSIONS}

\subsection{Mechanical Properties}

The tensile strength and Young's modulus of the modified epoxy matrix and glass fiber composite is as depicted below in Figure 3 and 4 respectively.

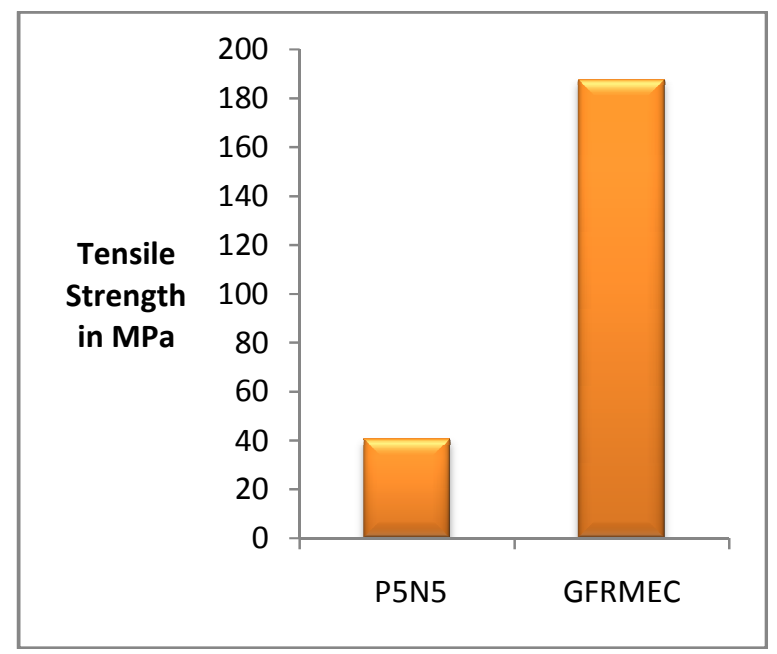

Fig 3: Tensile strength of modified epoxy matrix $\{$ P5N5 $\}$ and glass fiber reinforced modified epoxy composite $\{$ GFRMEC

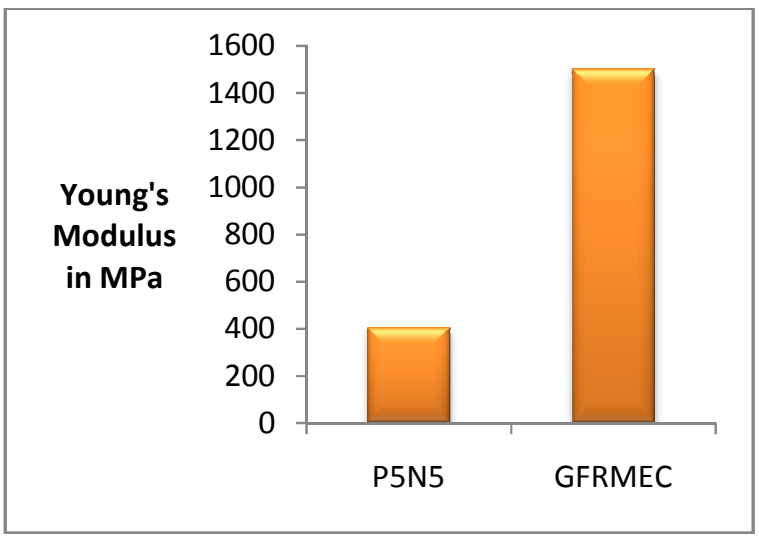

Fig 4: Young's Modulus of modified epoxy matrix $\{$ P5N5 $\}$ and glass fiber reinforced modified epoxy composite $\{$ GFRMEC $\}$

The increase in tensile property of the glass fiber reinforced modified epoxy matrix may be attributed to enhanced fibermatrix interfacial bonding as a result of which there has been effective transfer of the load from the matrix to the fibers.

The impact strength of the modified epoxy matrix and glass fiber composite is as depicted below in Figure.5.

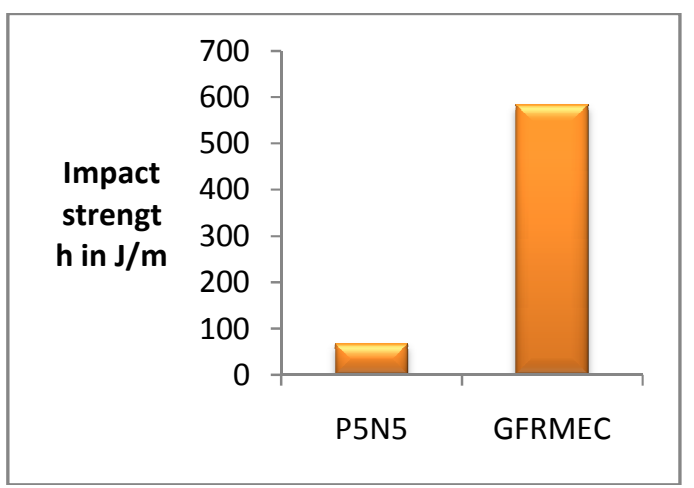

Fig 5: Impact strength of modified epoxy $\{\mathrm{P} 5 \mathrm{~N} 5\}$ and glass fiber reinforced modified epoxy composite\{GFRMEC

Samples that were used in this testing were notched. The notches in the izod impact specimen serve to concentrate the stress, minimise plastic deformation, and direct the fracture to the part of the specimen behind the notch. Incorporation of NBR into P5N5 blend resulted in matrix ductility and hence an improvement in the impact strength value. The improvement in impact strength shall be correlated with toughness enhancement. Significant toughening is achieved only when the rubber can form a separate phase inside the epoxy matrix with a particle size in the order of few micrometers. The SEM micrograph of the P5N5 blend show two distinct phases, a homogeneous phase containing the epoxy and PMMA and a second phase of separated spherical embedded rubber 
particles. Further the glass composite shows an increase in impact strength indicating that there is substantial matrix and fiber interfacial bonding, and the fiber is able to redistribute the stress to new area.

The flexural strength of the modified epoxy matrix and glass composite is as depicted below in Figure. 6

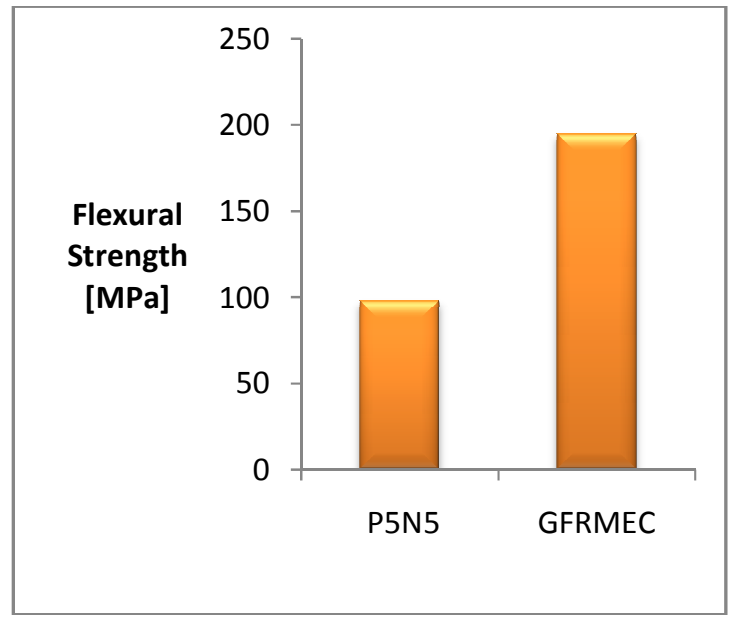

Fig 6: Flexural strength of modified epoxy $\{$ P5N5 $\}$ and glass fiber reinforced modified epoxy composite $\{$ GFRMEC $\}$

Flexural strength gives the unit resistance to the maximum load before failure by bending stresses. The flexural strength of the matrix was substantially increased by reinforcement with glass fibers. This increase revealed good wetting/ adhesion of the matrix to the fiber.

The fracture toughness value of the modified epoxy matrix and glass composite is as depicted below in Figure. 7.

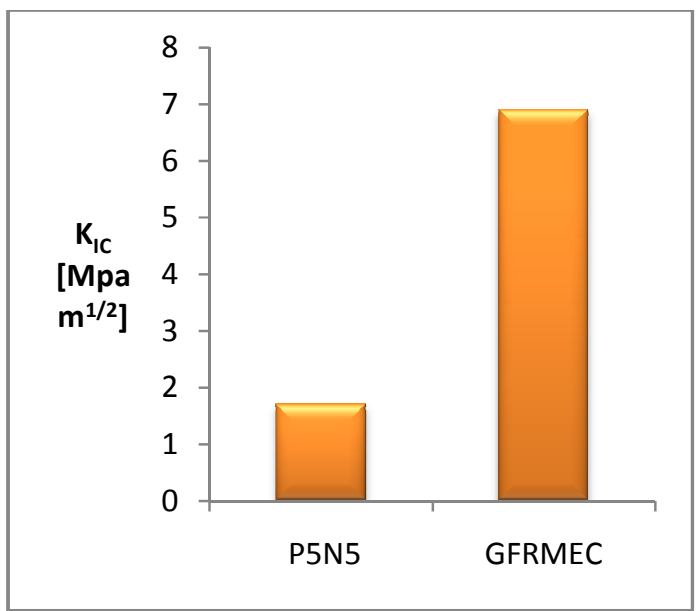

Fig 7: Fracture toughness of modified epoxy $\{$ P5N5 $\}$ and glass fiber reinforced modified epoxy composite $\{$ GFRMEC
The fracture toughness of the composite increased significantly. In toughened matrices the type of reinforcement, resin/ reinforcement interaction, ply stacking sequence, fatigue properties, interleaving etc. play a significant role in determining the toughness of laminate composites. The woven fabric of glass leads to polymer rich region at the strand cross-over points and in these regions the extensive energy dissipating plastic deformation can occur which arises from multiphase microstructure. The substantial increase in fracture energy may be attributed to the fact that toughening mechanisms like shear banding and plastic deformation zone in the matrix have occurred.

\subsection{Morphological Analysis}

The scanning electron micrographs of P5N5 blend display rough fracture surfaces [Figure .8]. The magnified P5N5 micrograph shows the crack propagation mostly through the epoxy matrix, around the rubber particles [Figure.9]. The toughening effect is made possible by the formation of two phase system. The rubber has precipitated out of the mixture during the polymerization process. The difference in the solubility due to acrylonitrile content causes the rubber to precipitate out into spherical particles. The presence of embedded soft spherical particles stimulates shear deformation mechanism because points of maximum stress concentration develop around the equators of such particles when the resin is stressed. Further void formation is promoted and yielding constraints adjacent to failed particle are reduced. The resulting plastic deformation helps to blunt a propagating crack tip and suppress fracture.

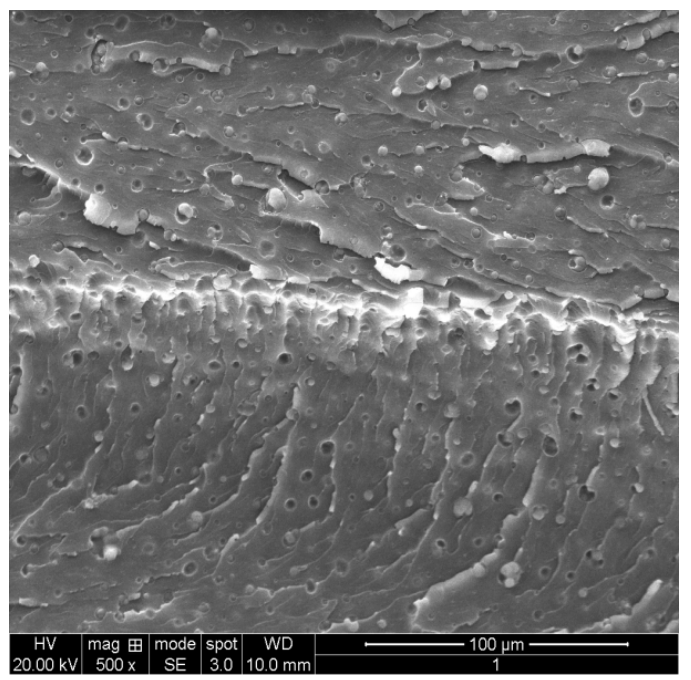

Fig.8 Rough surface of the P5N5 blend seen with holes and stress whitening. 


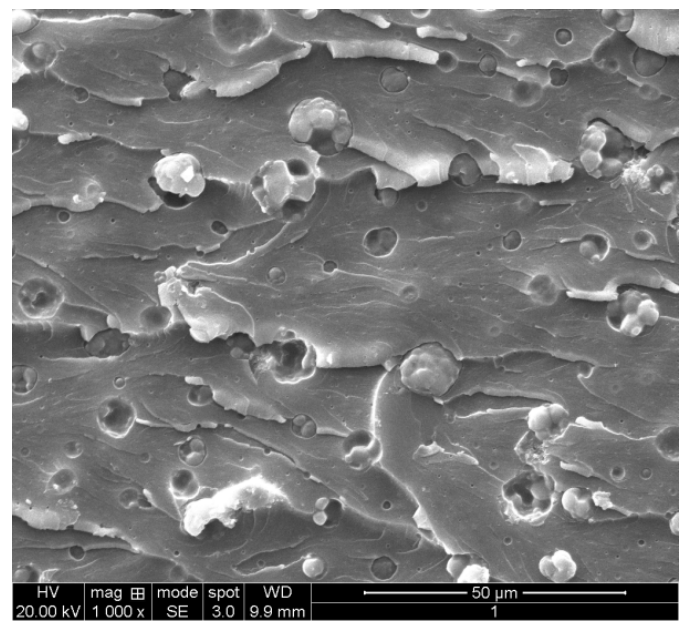

Fig. 9. The magnified P5N5 micrograph shows the crack propagation occurring mostly through the epoxy matrix around the rubber particles.

The morphology of the composite was investigated by means of scanning electron microscopy. Morphology studies of GFRMEC revealed that the use of modified epoxy matrix has lead to better adhesion between the matrix and the fiber indicating good wetting and strong interface. The evidence for the same is provided from the matrix traces seen on the surface of the fiber. Very little fiber pull out suggests that the modified epoxy matrix has been efficient in holding on to the fibers. In addition most fibers on the fractured surface were oriented in the flowing direction of the molding. This indicates that the composites have higher degree of fiber orientation under the stress, which results in higher fiber efficiency factor and hence higher mechanical strength. The glass fibers protruding from the composite indicate the degree of fiber pull out and crack deflection. The fiber surfaces that protrude are not clean with some adhering matrix material on it further indicating that the fibers are well adhered to the matrix.

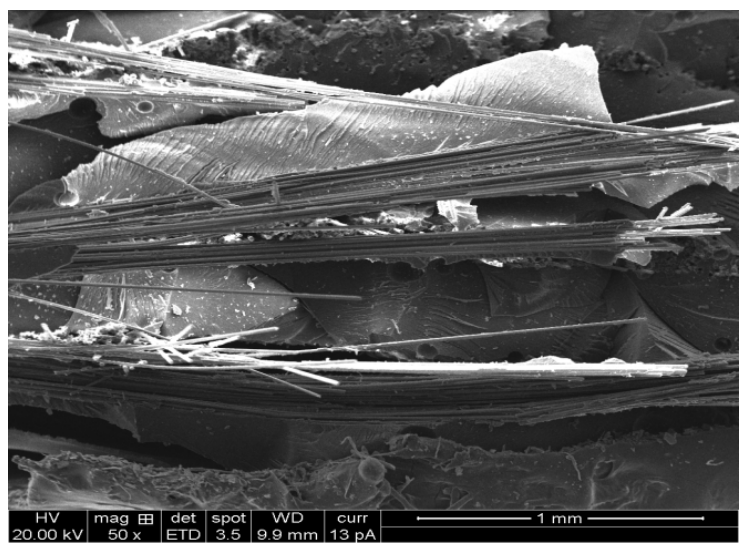

Fig 10: The fibers well embedded in the modified epoxy matrix.

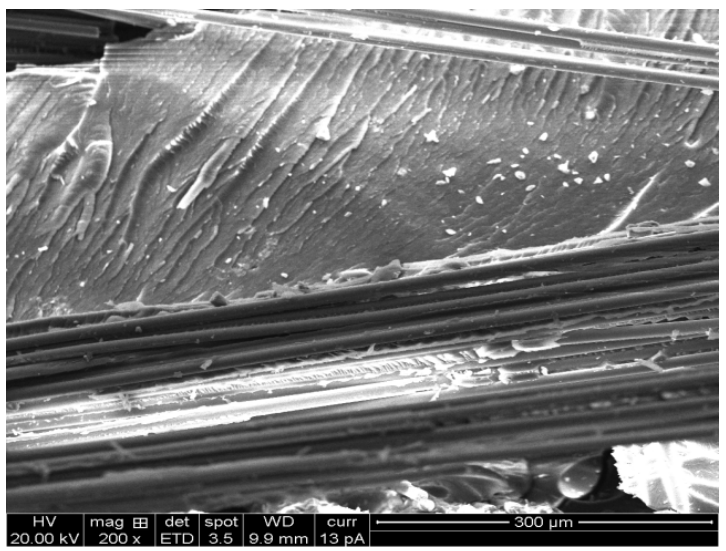

Fig 11: The crack propagation seen occuring through the modified epoxy matrix.

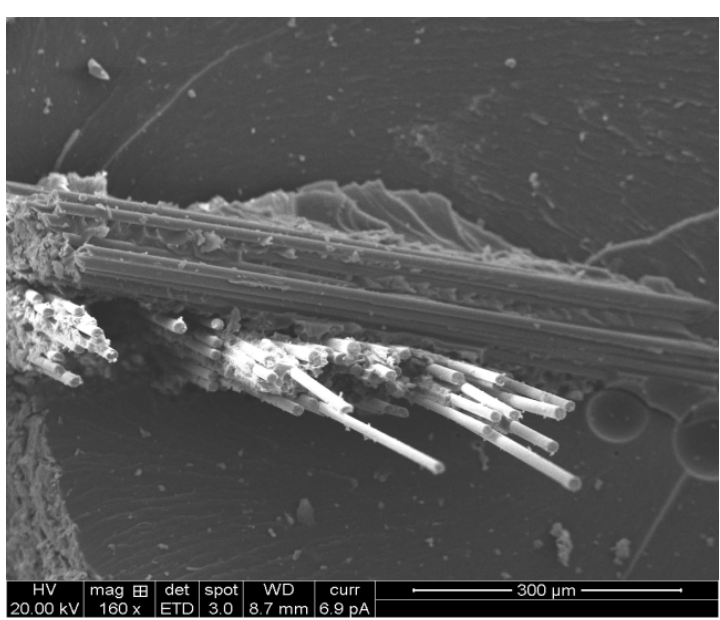

Fig 12: Fiber pull out and fiber breakage leading to better toughness.

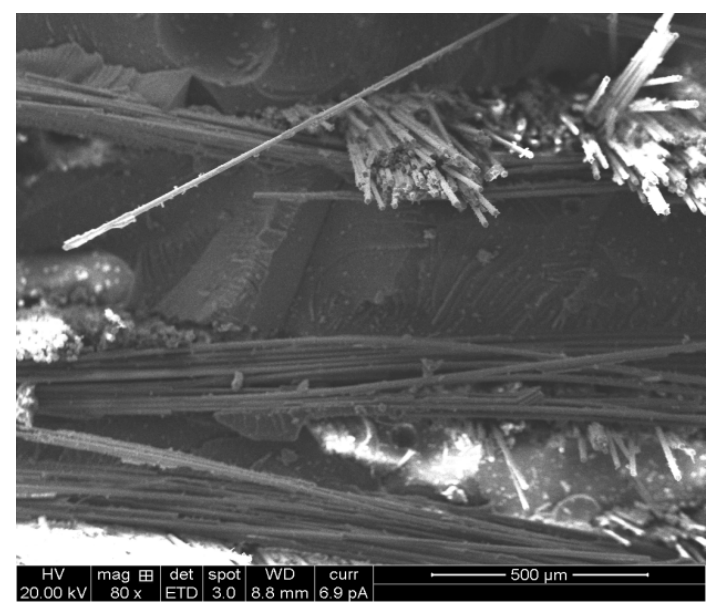

Fig 13: The micrograph depicting fiber pull out, fiber fracture, fiber/matrix debonding. 


\section{CONCLUSIONS}

It has been observed that the modified epoxy matrix may be considered as an excellent matrix for potential composite preparations. The substantial enhancement in the mechanical properties of the GFRMEC does indicate good adhesion between the matrix and the fibers. Hence this modified epoxy matrix may be used to develop various other composites containing different reinforcing materials and the study of their mechanical and morphological properties can be carried out.

\section{ACKNOWLEDGEMENTS}

The author wishes to thank Mr. Ganesh M, Managing Director, GLS polymers in extending his help in carrying out mechanical characterisation of the specimens in his lab and Mr. Srinivasa Urala in helping with design and fabrication of moulds to characterise the specimens.

\section{REFERENCES}

[1]. Jang BZ. Advanced polymer composites: principles and applications. ASM Int 1994.

[2]. Ellis B. Chemistry and technology of epoxy resins. Glasgow: Blackie; 1993.

[3]. Verchere D, Pascault JP, Saterau H, Moschiar SM, RiccardiCC, Williams RJJ. Rubber-modified epoxies. 4. Influence of morphology on mechanical-properties. J Appl Polym Sci 1991;43(2):701-16.

[4]. Pascault JP, Sautereau H, Verdu J, Williams RJJ. Thermosetting polymers. Marcell Decker; 2002.

[5]. Arias ML, Frontini PM, Williams RJJ. Analysis of the damage zonearound the crack tip for two rubber-modified epoxy matricesexhibiting different toughenability. Polymer 2003;44(5):1537-60.

[6]. Shukla SK, Srivastava D. Blends of modified epoxy resin andcarboxyl-terminated polybutadiene. J Appl Polym Sci 2006;100(3):1802-8.

[7]. Russell B, Chartoff R. The influence of cure conditions on the morphology and phase distribution in a rubber-modified epoxy resinusing scanning electron microscopy and atomic force microscopy. Polymer 2005;46(3):785-98.

[8]. Kar S, Banthia AK. Synthesis and evaluation of liquid amine terminated polybutadiene rubber and its role in epoxy toughening. J Appl Polym Sci 2005;96(6):2446-53.

[9]. Tercjak A, Serrano E, Remiro PM, Mondragon I. Viscoelastic behavior of thermosetting epoxy mixtures modified with syndiotactic polystyrene during network formation. J Appl Polym Sci 2006;100(3):2348-55.

[10]. Salmon N, Carlier V, Schut J, Remiro PM, Mondragon I. Curing behaviour of syndiotactic polystyrene-epoxy blends. 1 . Kinetics of curing and phase separation process. Polym Int 2005;54(4):667-72.

[11]. Francis B, Ramaswamy R, Rao VL, Jose S, Thomas S, Raju KVSN .Morphology, viscoelastic properties, and mechanical behavior of epoxy resin modified with hydroxyl- terminated poly(ether ether ketone) oligomer with pendent tert-butyl groups. Polym Eng Sci 2005;45(12):1645-54.

[12]. Pan.N "Theoretical determination of the optimal fiber volume fraction and fiber-matrix property compatibility of short fiber composites polymer." Polym. Comp.,1985, 14(2), 993

[13]. F.R.Johns, Hand Book of Polymer-Fiber Composites, Longman Scientific and Technical, 1994

[14]. Piggott.M.R “ A new model for interface-failure in fibrereinforced polymers.” Comp. Sci. Technol. 1995, 55(3),269

[15]. Okorofor E. U, Priston A.M, Hill.R "Adhesion in fiber reinforced plastics investigated by means of acoustic emission" Int. J. Adhesion and Adhesives, 1996, 16(3), 141

\section{BIOGRAPHIES}

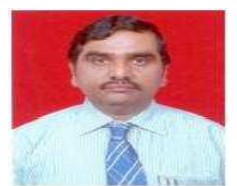

Dr. K. Natarajan is the inventor of TGPPD epoxy resin and NCCS cable seal. Two patent holder, he is the recipient of the prestigious National award for his invention of NCCS cable seal. He is currently the HOD of Chemistry Dept.\& Director, Advanced Polymer Material Lab (APML), R.V.College of Engineering,

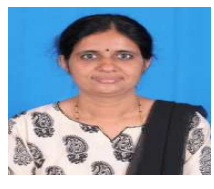

Padma C. B, co-author of the research paper, is a $\mathrm{PhD}$ scholar from R.V. College of Engineering. Currently working in the area of polymer resin modification, composite processing and characterization. 